
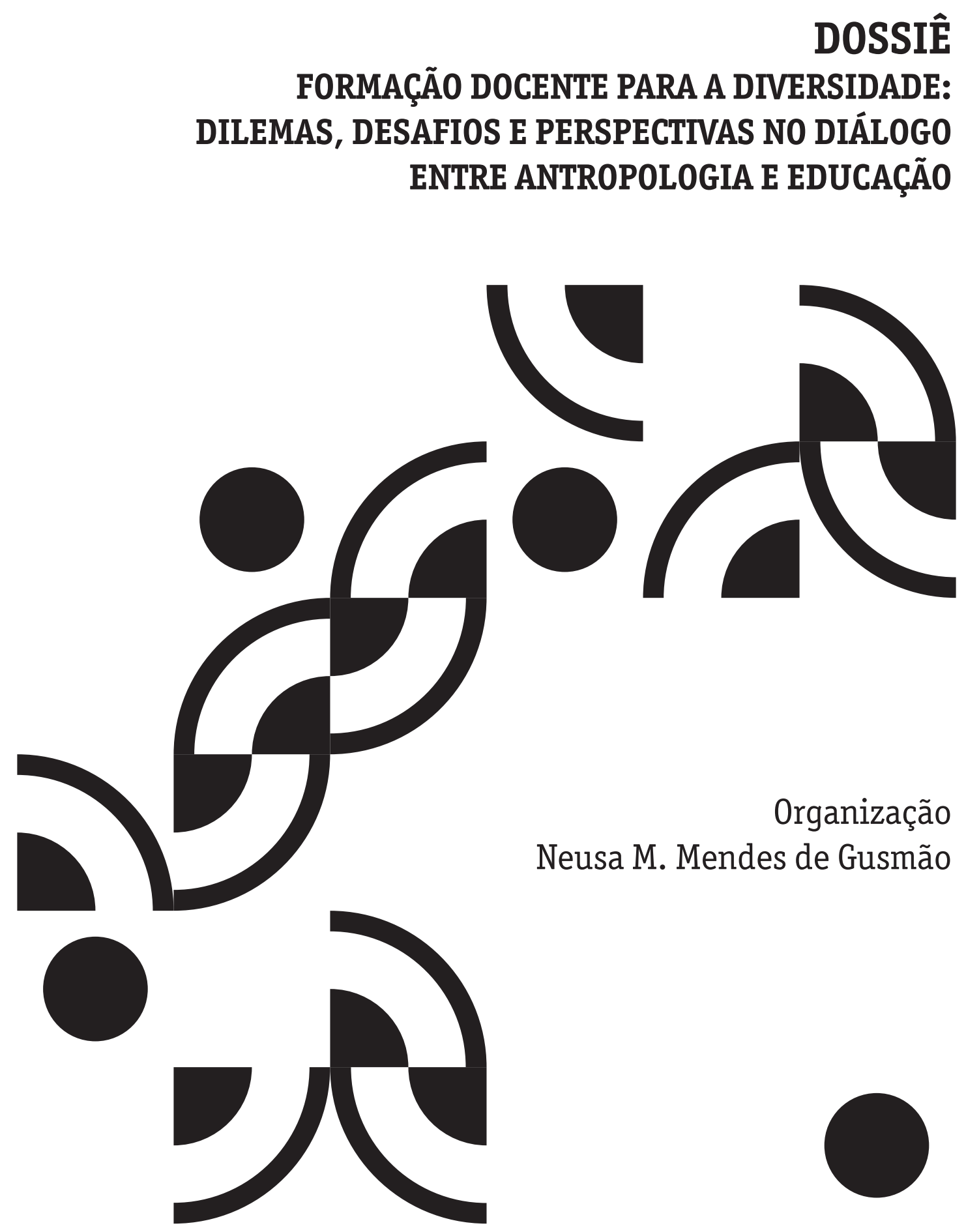


\section{Apresentação do dossiê \\ Formação docente para a diversidade: \\ dilemas, desafios e perspectivas no diálogo entre Antropologia e Educação}

Neusa M. Mendes de Gusmão*

0 presente Dossiê coloca em diálogo a Antropologia e seu método no campo educacional. Tal diálogo implica o ter que reconhecer a heterogeneidade do social, com múltiplas experiências, e assumir a teoria e a prática como elementos inseparáveis na construção do conhecimento, marcas do método antropológico diante de sujeitos diversos - da realidade indígena à realidade étnica e cultural presente na sociedade brasileira. Em questão, as Ciências Sociais e, em particular, a Antropologia, diante de campos distintos, com tradições também distintas e elementos em comum, como é o caso da Educação. Nesse sentido, dois autores - Amurabi Oliveira e Rodrigo Rosistolato - apresentam um debate que cobre a tradição antropológica num longo espectro temporal e teórico: do século XIX ao século XXI. Para ambos, ainda hoje, o que há é o desconhecimento da Antropologia e do fazer antropológico no campo educacional.

Rosistolato mostra que, em pleno início da década de 2000, a professora que o recebe na escola quer "saber se você [o antropólogo] sabe fazer formação de professores com antropologia, só isso. Vocêsabe?”. Segundo ela, "eles[professores] não estão acostumados com antropólogos". Para o autor, trata-se de "resistências aos discursos externos [à escola], veiculados pelo Estado ou por especialistas em Educação que não se encontram na escola".

Mas, como aponta Oliveira, trata-se também de desconhecimento do percurso da Antropologia, que se coloca para os próprios antropólogos em termos da trajetória e da conforma-
* Professora titular e colaboradora do Departamento de Ciências Sociais na Educação (Decise) da Faculdade de Educação da Unicamp, Campinas, SP, Brasil. neusagusmao@uol.com.br. 
ção de uma Antropologia brasileira, que deve muito à Educação. Seu relato fala de uma "Antropologia Pedagógica" do passado (século XIX), que se estende às Escolas Normais no Brasil, passando pelo Gabinete de Psicologia e Antropologia Pedagógica da Normal da Praça, em São Paulo. Oliveira aponta, ainda, uma Antropologia física e biológica do século XIX e início do século XX, distanciada e esquecida da Antropologia que iria se constituir nos meios universitários emergentes a partir dos anos de 1930, com a institucionalização de uma Antropologia brasileira de cariz cultural. Para o autor, “pensar a Antropologia brasileira é pensar sua íntima relação com a Educação e com o processo formativo docente", mas isso não é lembrado.

A formação para a diversidade, como parte de um campo de tensão de natureza política, envolve perdas e ganhos e implica uma rede diferencial de interesses e de poder que regula o conhecimento científico, tanto na Antropologia como na Educação. 0 fato exige distinguir as “comunidades da prática" no interior das coletividades em que se atua como professor, educador e pesquisador. É nesse sentido que o intenso processo de imersão etnográfica se apresenta nos relatos dos autores, para situar a interface da Antropologia com a Educação, a partir da Antropologia social e cultural que se configurou na institucionalização dessa ciência no Brasil e que reverbera até os dias atuais.

Os autores aqui propostos assumem como de suma importância discutir o papel de uma Antropologia social e cultural, como fundamental na compreensão de aspectos marginais e/ou de sujeitos minorizados do mundo social, a reivindicar um lugar próprio e autônomo no mundo social por meio da Educação. Este é o caso que se apresenta no texto elaborado por Rocha, Russi e Alvarez, que trazem a questão da escola numa população ribeirinha - caso Macedônia - e numa comunidade indígena - caso Santidade. Também Grupioni aborda a questão da formação de professores indígenas para escolas localizadas nas aldeias. Ambos os textos revelam a atuação de antropólogos em contextos interdisciplinares de formação, decorrentes de políticas públicas que se estruturaram no Brasil a partir dos anos de 1980/90.

Tais políticas chegam aos dias de hoje, evidenciando percursos de luta e de construção de autonomia das comunidades em estudo, com perspectivas de valorização de práticas culturais, línguas, etc. Grupioni mostra como evoluíram os processos de formação dos professores indígenas até os dias atuais, em que as comunidades indígenas, a partir de um modelo próprio de formação, tomam 
por princípio formar indivíduos do próprio grupo para atuar nas comunidades; e, com isso, deram origem a uma nova política pública por parte do Estado. No caso de Macedônia e Santidade, trata-se de um projeto de extensão e pesquisa voltado à formação de professores da rede pública de ensino. A perspectiva de atuação conduz os pesquisadores e os antropólogos a formular uma proposta de preservação de patrimônios materiais e imateriais que ordena a prática de formação com essas populações e constitui uma "Etnoeducação Patrimonial" não restrita à questão étnica. A etnoeducação resulta de ações mediadoras entre conhecimento e ação, saberes cotidianos e ensino "formal", a partir da experiência partilhada com antropólogos, psicólogos, educadores, comunidades e alunos, numa clara concepção de interdisciplinaridade típica da Antropologia.

A união ação e teoria ou teoria e prática, aspecto central na Antropologia, é evidenciada, também, no conjunto dos demais textos deste Dossiê. 0 intuito de cada um dos relatos é a construção de alternativas no processo educativo, que possibilitem a descoberta conjunta de meios de ação e reflexão; portanto, que instaurem o compromisso com a realidade e com a vida.

O campo disciplinar acadêmico da Antropologia como ciência está conso- lidado, mas o fato não impede o debate em torno de métodos e abordagens, tal como se espera no universo de uma ciência e no de seu desenvolvimento, como diz Montero (apud Ferrari, 2011). Nesse sentido, as abordagens que sistematizam o pensamento e o fazer antropológico na Educação se apresentam como não definidas por um modo único de produzir conhecimento, constituindo um campo em construção e de muitas possibilidades. Esta a razão de ter que se pensar criticamente o fazer científico, de modo a ressaltar que este não pode ser apenas e eminentemente teórico, mas também não pode ter por foco a prática acima de qualquer reflexão crítica assentada num corpus teórico consistente. Nesse sentido, o engajamento do antropólogo e a antropologia por ele praticada exigem comparar diferentes posições, situá-las, já que importa a concepção de ciência que adotamos na explicação desta ou daquela realidade.

No caso da Antropologia e da Educação, por se tratar da transposição de um campo a outro do saber, importa ainda refletir criticamente sobre os sentidos que a noção de cultura assume. A razão está em que na educação, principalmente escolarizada, a noção de cultura quase sempre é apreendida no interior de uma concepção instrumental, sem o embasamento teórico que a sustenta, e 
isso exige colocar estudos e práticas sociais e pedagógicas em alerta.

Nesse contexto, a experiência docente é retomada no texto de Cerletti, ao pensar uma realidade outra. Em questão, a forma como se dão os processos de etnografia educativa centrados no cotidiano; a possibilidade da transformação educativa a partir da valorização do saber docente diferenciado do discurso pedagógico; e a recuperação da noção de família, para expor as múltiplas experiências que configuram o processo formativo ligado a outros aspectos da vida, além da escola. Nesse sentido, Cerletti coloca em discussão a experiência formativa de professores e professoras, a relação escola-família num trabalho empírico realizado num bairro de Buenos Aires, para estabelecer a posição docente como construção ativa permeada por contradições e paradoxos que se refletem no trabalho de ensinar.

A perspectiva de uma etnografia educacional, presente no texto de Cerletti, é proposta por Elsie Rockwell e Justa Espeleta¹, investigadoras do DIE (México), e reflete o debate atual a respeito de uma possível Antropologia e Educação/Antropologia da Educação na América Lati-

1. A referência é especificamente a estas autoras, na medida em que no DIE atuam outros pesquisadores, com distintas leituras da etnografia, e a obra delas é que teve largo alcance no Brasil e na Argentina, como diz Tosta em texto deste Dossiê. na. O campo disciplinar ainda em constituição no Brasil e na Argentina, em uma de suas vertentes, apropria-se da perspectiva proposta e, nestes dois países, as consequências no campo da pesquisa e da produção do conhecimento tomam caminhos diferentes. É desse debate que fala o texto de Tosta, na medida em que, comparando pesquisas realizadas no Brasil e na Argentina, tenta compreender o campo disciplinar em formação.

0 texto de Vieira, pesquisador português, cruza o Atlântico e faz eco aos textos citados do lado de cá do oceano, para apontar o debate português em torno das possibilidades de uma Antropologia da Educação que tenha como centro a formação docente para a diversidade, em termos de processos reflexivos e interculturais, possibilitados pela etnobiografia como ferramenta pedagógica. Trata-se de tomar o conhecimento escolar e o conhecimento de outros contextos culturais como centrais para construir, de forma reflexiva, a formação e a prática docente para a diversidade, já que deles resulta "a construção das pessoas que vivem, cada vez mais, entre diversos mundos culturais". Nessa medida, Vieira define a Antropologia da Educação “como o estudo dos processos educativos ou, mesmo, de como os humanos aprendem, seja na escola, na família, na rua ou em toda sua trajetória social”, disso resul- 
tando as identidades pessoais. Desse modo, diferenciando-se da perspectiva em voga na América Latina, o autor aponta para o fato de que a Antropologia da Educação “não se resume, apenas, ao uso da etnografia em contextos educativos na escola, fora da escola, na família, nos tempos livres, etc.”. Segundo ele, diz respeito também às "metamorfoses culturais que ocorrem na vida das pessoas" e que implicam em auto e heteroconstrução e reconstrução de si mesmo. Compreender histórias de vida e processos de socialização vividos por aquele que ensina e educa permite melhor situar sua prática docente e se faz contributo reflexivo para a diversidade cultural.

De todos os textos deste Dossiê emerge, com força, o fato de que a Antropologia, qualquer que seja o ponto de partida - Educação ou Ciências Sociais revela ser uma e outra relação "pouco exploradas, pouco trabalhadas" por antropólogos, cientistas sociais ou educadores, como o demonstra Oliveira. Resulta daí uma imensa dificuldade no recorte a ser feito, de modo a demarcar tanto o desenvolvimento de uma área e outra, como as relações entre ambas. Nesse sentido, o diálogo entre campos diversos constitui um campo de tensão e de "relações perigosas", nem por isso menos fecundo e legítimo diante da realidade de nosso tempo. Este é o contexto que se imprime neste dossiê: o debate entre áreas, não qualquer área, mas, particularmente, a Antropologia e a Educação.

Fazendo nossa a fala de Rocha, Russi e Alvarez sobre o trabalho que realizam em Oriximiná, podemos dizer que estudos como os que aqui se apresentam "nos colocam na fronteira de outros mundos" e fazem com que a Antropologia e o trabalho de campo permitam o diálogo com outras ciências, outros campos, num largo espectro: das ciências físicas e biológicas às ciências humanas e sociais, do passado e do presente. Nesse diálogo, será o trabalho de campo que irá moldar, num e noutro esforço de investigação sobre diferentes temas, um olhar capaz de captar problemáticas relativas à Educação no interior deste ou daquele grupo em estudo pelo antropólogo. Contudo, a Educação aparece nos estudos antropológicos como complementar aos estudos de um investigador em campo e raramente se faz objeto central da investigação, gerando desconhecimento e desconforto, quando da presença do antropólogo em espaços, como, por exemplo, a escola, nos quais não tem sido frequente sua presença ou a dos conteúdos da ciência que pratica. 0 texto de Rosistolato reflete esta questão, ao tratar de projetos de orientação sexual na escola. Ele relata a resistência à sua presença - um antropólogo? Teria 
ele algo a dizer na formação de professores? E revela também o silenciamento de professores e professoras, nos debates em sala de aula com o tema que é resultado do que postulam os PCN e que alterou significativamente as funções da escola e deu nova configuração ao trabalho com orientação sexual/sexualidade.

Assim, dar visibilidade ao fazer da Antropologia é um desafio que todos os textos deste Dossiê explicitam, ao tratar dos processos educativos não restritos à escola. Nesse movimento, o que os textos apresentam permite expor não apenas princípios da Antropologia e de seu fazer, mas também os conteúdos antropológicos vistos como capazes de dotar a formação docente para a diversidade de instrumental significativo e importante na transformação da sociedade.

O mal-estar suscitado pela presença do antropólogo (Rosistolato) na escola evidencia a ausência desse campo disciplinar no currículo de formação de professores. Tais conteúdos estão ausentes no trato das diversidades sociais e culturais, hoje demandadas como exigência e direitos por movimentos sociais e aparatos legais que incidem sobre a escola. Aqui, o valor das exposições feitas por Rocha, Russi e Alvarez, e, ainda, por Grupioni, no contexto das práticas de formação das populações ribeirinhas, quilombolas, indígenas.
Os exemplos trabalhados pelo conjunto de autores como exercício da prática antropológica revelam um paradoxo, já apontado por Silva. Segundo a autora (2001, p. 9):

São raros no Brasil, os estudos antropológicos sobre educação. São, porém, numerosas e significativas as participações dos antropólogos em projetos educacionais que envolvem diferentes setores da população.

O paradoxo só faz agravar-se, quando se tem em mente o fato de que a Antropologia brasileira sequer tem cogitado a possibilidade de uma Antropologia da Educação na maioria dos cursos de formação de professores; e também não cogita a Educação como objeto central de suas pesquisas ou da formação do próprio antropólogo. Parodiando Iturra (s.d.), é aqui que o antropólogo se faz o pior inimigo da Antropologia. É aqui, também, que reside um grande entrave de desenvolvimento desse campo - Antropologia da Educação -, que apenas muito recentemente vem sendo colocado e revisto. Em nosso país, apesar da raridade dos estudos antropológicos sobre Educação, como aponta Silva (2001), encontra-se em emergência e construção uma Antropologia da Educação, não atrelada apenas à questão in- 
dígena, mas ativa e atuante também em outros contextos, igualmente objeto de reflexão/atuação de outras ciências humanas. É disso que este Dossiê nos fala.

Os textos que se seguem portam aspectos comuns e também diversos; tratam de temas e de sujeitos sociais diferenciados entre si e/ou na realidade nacional; apontam para o fato de que, em diversos espaços acadêmicos - a partir dos quais tais estudos se desenvolvem -, ensaia-se a constituição de uma Antropologia da Educação. Contudo, quase sempre, imagina-se tal campo disciplinar como voltado para a questão da educação indígena e raramente se imaginam outros universos educacionais e processos educativos singulares. Fato que valoriza os textos deste Dossiê, por sua amplitude e diversidade.

A Antropologia tem ampliado seu círculo de influência e intensificado sua presença em outros cursos, dentre os quais, os de Pedagogia ou de formação de professores, bem como nas pesquisas educacionais que se dizem de "cunho etnográfico". Mas enfrenta ainda um desafio: o de se fazer compreender como ciência específica e, ao seu método e suas noções, como ferramentas de suportes teóricos também específicos. Porém, a Educação não conta - ou conta mal - com a compreensão do método investigativo da Antropologia, com proce- dimentos próprios e reconhecidos. Esta, a contradição de um tempo que não é apenas fruto da institucionalização de certo modo mais tradicional de educar, mas resulta de concepções pouco receptivas e pouco flexíveis a respeito do que seja conhecimento e do que seja ciência, num campo e noutro.

Dessa constatação, impõe-se a necessidade de levar alunos a refletir para além dos muros da escola, a construir outro olhar sobre esse espaço, a alargar a compreensão dos processos educativos e dos problemas inerentes a um contexto de marcada pluralidade cultural, como é o caso brasileiro. Dimensão com que este Dossiê espera contribuir, na medida em que a Antropologia, desde sempre, tem refletido sobre a diversidade humana e buscado um lugar de onde, podendo compreendê-la, se instaure um campo de direitos e de cidadania, no sentido atual do termo.

Qual seria, portanto, a proposta da Antropologia na formação de professores?

A reforma do ensino que implantou a LDB colocou-nos, como educadores, diante do desafio de formar um profissional da educação familiarizado, cada vez mais, com a diversidade dos modos de construir e viver a vida, numa sociedade que não é apenas plural, mas é também hierarquizada, marcada por 
contradições e conflitos. Nesse sentido, impõe-se, na teoria e na prática, definir e significar o que se entende por cultura e quais os mecanismos pelos quais ela opera a realidade social. Contudo, por sua polissemia, pelos entendimentos por vezes equivocados, o momento atual é crucial para a própria Educação em dois sentidos: no tocante ao campo científico da Antropologia, que remete à historicidade da noção de cultura e à interpretação legal da mesma noção, no âmbito dos aparatos legais que regem as políticas educativas no caso brasileiro.

0 debate não é de simples solução, seja na dimensão organizada de atuação política de antropólogos que estão em busca de caminhos, seja na prática cotidiana do professor na sala de aula, na qual entra em questão a sua própria formação. É este o ponto que coloca a experiência antropológica como ciência que oferece um diferencial a mais na formação do pedagogo como educador e pesquisador; e também oferece o mesmo diferencial em relação ao próprio antropólogo ou cientista social, quando reconhece a Educação como fundamental na formação de todo e qualquer cidadão. Aqui os aportes da Antropologia se tornam imensamente significativos, antes de tudo porque permitem compreender a valiosa contribuição dessa área para a reflexão crítica dos processos educativos, da escola e das políticas educativas que movimentam contextos históricos concretos.

Relembro, portanto, a epígrafe do livro de Kuper (2002, p. 19), que cita Albert O. Hirschman: "importa, não solucionar as questões, mas sim elevar o nível do debate". Esse o sentido aqui pretendido, já que não somos apenas seres culturais, mas necessitamos compreender o que é cultura, no aqui e agora de nossas existências, para podermos ir além dela e estabelecer comunicação e partilha entre sujeitos e mundos diferentes, e para sermos todos compreendidos como iguais e diferentes. Razão fundamental da conquista de um mundo melhor e mais equânime. 


\section{Referências bibliográficas}

FERRARI, M. A Antropologia não é ciência? Debate coloca fundamentos da disciplina em cheque. Revista FAPESP, São Paulo, n. 18, p. 78-81, mar. 2011.

ITURRA, R. O pior inimigo da Antropologia é o antropólogo. A Página, Arquivo Vivo, ano o, n. 1, [s.d.]. Entrevista concedida a Maria José Margarido. Disponível em: http:/ www.apagina.pt. Acesso em: 10 set. 2010.

KUPER, A. Cultura. A visão dos antropólogos. Bauru, SP: EDUSC, 2002.

SILVA, A. L. Uma “antropologia da educação” no Brasil? Reflexões a partir da escolarização indígena. In: SILVA, A. L.; FERREIRA, M. K. L. (Org.). Antropologia, história e educação. A questão indígena na escola. São Paulo: Global, 2001. p. 29-25. 